(6) OPEN ACCESS

\title{
Low prevalence of ideal cardiovascular health in Peru
}

\author{
Catherine P Benziger, ${ }^{1,2}$ José Alfredo Zavala-Loayza, ${ }^{1}$ Antonio Bernabe-Ortiz, ${ }^{1,3}$ \\ Robert H Gilman, ${ }^{4,5}$ William Checkley, ${ }^{4,6}$ Liam Smeeth, ${ }^{3}$ German Malaga, ${ }^{1,7}$ \\ Juan Jaime Miranda, ${ }^{1,7}$ CRONICAS Cohort Study group
}

- Additional material is published online only. To view, please visit the journal online (http://dx.doi.org/10.1136/ heartjn-2017-312255).

${ }^{1}$ CRONICAS Center of Excellence in Chronic Diseases, Universidad Peruana Cayetano Heredia, Lima, Peru

${ }^{2}$ Division of Cardiology, University of Washington, Seattle, WA, USA

${ }^{3}$ Faculty of Epidemiology and Population Health, London School of Hygiene andTropical Medicine, London, UK ${ }^{4}$ Department of International Health, Johns Hopkins University, Baltimore, MD, USA ${ }^{5}$ Research Division, Asociación Benéfica PRISMA, Lima, Peru ${ }^{6}$ Division of Pulmonary and Critical Care, School of Medicine Johns Hopkins University, Baltimore, MD, USA ${ }^{7}$ Facultad de Medicina "Alberto Hurtado", Universidad Peruana Cayetano Heredia, Lima, Peru

\section{Correspondence to}

Dr Juan Jaime Miranda, CRONICAS Centre of Excellence in Chronic Diseases, Universidad Peruana Cayetano Heredia, Av. Armendáriz 497, Miraflores, Lima 18, Peru; jaime.miranda@ upch.pe

Received 3 August 2017 Revised 3 November 2017 Accepted 6 November 2017 Published Online First 11 January 2018

\section{SLinked}

- http://dx.doi.org/10.1136/ heartjnl-2017-312562

\section{Check for updates}

To cite: Benziger $C P$, Zavala-Loayza JA, BernabeOrtiz $A$, et al. Heart 2018;104:1251-1256

\section{ABSTRACT \\ Background The prevalence of and factors} associated with ideal cardiovascular health (ICH) by sociodemographic characteristics in Peru is not well known.

Methods The American Heart Association's ICH score comprised 3 ideal health factors (blood pressure, untreated total cholesterol and glucose) and 4 ideal health behaviours (smoking, body mass index, high physical activity and fruit and vegetable consumption). ICH was having 5 to 7 of the ideal health metrics. Baseline data from the Center of Excellence in Chronic Diseases, a prospective cohort study in adults aged $\geq 35$ years in 4 Peruvian settings, was used $(n=3058)$.

Results No one met all 7 of ICH metrics while 322 $(10.5 \%)$ had $\leq 1$ metric. Fasting plasma glucose was the most prevalent health factor (72\%). Overall, compared with ages 35-44 years, the 55-64 years age group was associated with a lower prevalence of $\mathrm{ICH}$ (prevalence ratio $0.54,95 \% \mathrm{Cl} 0.40$ to $0.74, \mathrm{P}<0.001$ ). Compared with those in the lowest tertile of socioeconomic status, those in the middle and highest tertiles were less likely to have $\mathrm{ICH}$ after adjusting for sex, age and education $(\mathrm{P}<0.001)$.

Conclusion There is a low prevalence of $\mathrm{ICH}$. This is a benchmark for the prevalence of ICH factors and behaviours in a resource-poor setting.

\section{INTRODUCTION}

Ideal, intermediate and poor cardiovascular health was defined by the American Heart Association (AHA) 2020 Impact goals and has shifted the focus globally on promotion of health and control of risk rather than solely on prevention and treatment of disease. ${ }^{12}$ Ideal health is the simultaneous presence of three ideal health factors (normal cholesterol, normal blood pressure and no diabetes) and four ideal health behaviours (non-smoking, normal weight, high physical activity and ideal diet). ${ }^{2}$ Prior studies suggest that individuals with 5,6 or 7 ideal cardiovascular health (ICH) metrics have up to 10 times lower levels of ischaemic heart disease, cardiovascular disease (CVD) mortality, stroke ${ }^{3}$ and all-cause mortality compared with those with 0 to $1 \mathrm{ICH}$ metric. ${ }^{4-7}$ Prevalence and outcome estimates of ICH metrics in Latin America are lacking. ${ }^{4}$ Peru offers an opportunity to assess the impact of geographical variation on cardiovascular risk by combining settings on the spectrum of both ruralurban development as well as lowland-highland scenarios. Disparities in cardiovascular risk factors have been described by age, sex, ethnicity and geographical region in other populations, ${ }^{5-14}$ but limited data exist in Latin America. ${ }^{11} 13$

The objective was to determine the prevalence of ideal, intermediate and poor cardiovascular health in a Latin American population, as well as calculate the mean cardiovascular health score by sociodemographic characteristics in Peru.

\section{METHODS}

\section{Study design, setting and participants}

Design of the Center of Excellence in Chronic Diseases (CRONICAS) study were reported previously. ${ }^{15}$ CRONICAS is a prospective age-stratified and sex-stratified cohort study in adults aged $\geq 35$ years in four Peruvian settings: Lima (Peru's capital, costal urban, highly urbanised), urban and rural Puno (both high-altitude) and Tumbes (costal semirural). Randomly selected participants by sex and age groups (aged 35-44, 45-54, 55-64 and $65+$ years) were taken from census data at each study site. Data from baseline (collected in 2010) were used. Exclusion criteria included pregnant women, those unable to provide informed consent or respond to the questionnaires and bedridden individuals.

\section{Data collection}

A team of community health workers was trained to enrol participants and to conduct the questionnaires assessing sociodemographic and behavioural factors. Sociodemographic variables included sex, age groups, study site, education level and socioeconomic status (an aggregation of assets and household facilities into a wealth index and divided in tertiles $\left.{ }^{16}\right)$.

\section{American Heart Association definition of ICH}

$\mathrm{ICH}$ was defined as the simultaneous presence of ideal health factors (untreated blood pressure $<120 /<80 \mathrm{~mm} \mathrm{Hg}$, untreated total cholesterol (TC) $<200 \mathrm{mg} / \mathrm{dL}$ and untreated fasting plasma glucose $<100 \mathrm{mg} / \mathrm{dL}$ ) and ideal health behaviours (never smoker, body mass index (BMI) $<25 \mathrm{~kg} / \mathrm{m}^{2}$, moderate physical activity $\geq 150 \mathrm{~min} /$ week and ideal diet with four of the five components of the Dietary Approach to Stop Hypertension (DASH) diet). ${ }^{17}$ ICH was described in two ways: (1) percentage of the population with $\mathrm{ICH}$ (5-7 ideal metrics) and (2) mean healthy lifestyle score (range from 0 to 7). Intermediate and poor cardiovascular health were also assessed (3-4, and 0-2 ideal metrics, respectively). Participants self-reported their health in the question, "Would you consider that your health is: 
very good, good, regular, bad and very bad". The perception of health was also compared with the ICH score.

\section{Assessment of ICH factors}

Participants were invited to a clinic visit where systolic (SBP) and diastolic (DBP) blood pressure were measured in triplicate with the mean of the last two measurements used for the analysis. ${ }^{15}$ Total cholesterol, triglycerides and high-density lipoprotein cholesterol (HDL-c) were measured in serum, whereas fasting glucose was assessed in plasma and samples were obtained and sent to central laboratories for processing. ${ }^{115}$

Ideal blood pressure was defined as blood pressure $<120 /<80 \mathrm{~mm} \mathrm{Hg}$ and without any antihypertensive medication, intermediate was SBP $120-139$ or DBP $80-89 \mathrm{~mm} \mathrm{Hg}$ or treated to blood pressure $<120 /<80 \mathrm{~mm} \mathrm{Hg}$, and poor was blood pressure $\geq 140 / \geq 90 \mathrm{~mm} \mathrm{Hg}$. Ideal total cholesterol was TC $<200 \mathrm{mg} / \mathrm{dL}$ and without any cholesterol-lowering medication, intermediate was TC $200-239 \mathrm{mg} / \mathrm{dL}$ or treated to $\mathrm{TC}<200 \mathrm{mg} / \mathrm{dL}$ and poor was $\mathrm{TC} \geq 240 \mathrm{mg} / \mathrm{dL}$. Ideal fasting blood glucose was $<100 \mathrm{mg} / \mathrm{dL}$ and without any glucose-lowering medication, intermediate was glucose $100-125 \mathrm{mg} / \mathrm{dL}$ or treated to $<100 \mathrm{mg} / \mathrm{dL}$ and poor was glucose $\geq 126 \mathrm{mg} / \mathrm{dL}$.

\section{Assessment of ICH behaviours}

BMI $\left(\mathrm{kg} / \mathrm{m}^{2}\right)$ was computed from weight and standing height, measured in the clinic setting. ${ }^{15}$ Ideal BMI was defined as 18.5$24.9 \mathrm{~kg} / \mathrm{m}^{2}$ and poor was BMI $\geq 30 \mathrm{~kg} / \mathrm{m}^{2}$.

Smoking was defined as ideal if self-report of never having smoked or a former smoker who quit $>12$ months ago. Intermediate smoking included those who quit within the past 1-12 months, and poor included daily smoker ( $>1$ cigarette/day or if former but last cigarette was in the past 1 month).

For dietary intake, a food questionnaire was used that assessed dietary patterns over the past month. ${ }^{15}$ Healthy diet score used to define ICH included fruits and vegetables $\geq 4.5$ cups/ day, fish $\geq 23.5 \mathrm{oz}$. /week, whole grains $\geq 31 \mathrm{oz}$. servings/day, sodium $<1500 \mathrm{mg} /$ day, added sugar in sugar-sweetened beverages $<450 \mathrm{kcal} /$ week. Since only $89(3 \%)$ participants met at least four of the five components of the diet, we used intake of fruits and vegetables $\geq 4.5$ times/day as a surrogate of ideal diet in the definition of ICH, as used in prior studies. ${ }^{9}{ }^{18}$ For this variable, discrimination between intermediate and poor nutrition status was not possible as it was dichotomised to ideal ( $\geq 4.5$ times/day) and poor ( $<4.5$ times/day).

Physical activity was based on both leisure time and transportation-based domain of International Physical Activity Questionnaire as recommended for Latin American populations. ${ }^{19}$ Ideal physical activity was $\geq 150 \mathrm{~min} /$ week moderate or $\geq 75 \mathrm{~min} /$ week vigorous or $\geq 150 \mathrm{~min} /$ week moderate and vigorous activity. Poor physical activity was no physical activity reported with intermediate activity as any other amounts of activity.

\section{Definition of treatment control for ICH factors}

Use of antihypertensive, cholesterol-lowering and glucose-lowering medications within the past month of interview was self-reported and the participant was categorised as either intermediate cardiovascular health or poor cardiovascular health based on their clinical or laboratory measurements for each metric and the threshold definitions for ideal control were stated above, in agreement with current clinical practice guidelines. ${ }^{19}{ }^{20}$ Poor control was defined as blood pressure $\geq 140 / \geq 90 \mathrm{~mm} \mathrm{Hg}$, total cholesterol $\geq 240 \mathrm{mg} / \mathrm{dL}$ and glucose $\geq 126 \mathrm{mg} / \mathrm{dL}$. Participants self-reported history of heart disease or stroke by a physician.

\section{Statistical analysis}

A description of the socio-demographic, behavioural and clinical variables overall and according to sex was performed. Participants that did not have all of the cardiometabolic factors measured were excluded from the analysis $(n=504$; primary reason for exclusion: no blood pressure recorded $n=387$ or incomplete diet questionnaire $n=56$ ). Continuous variables were presented as means with SD and compared by sex using t-tests. Categorical variables were described by frequencies and compared by sex using $\chi^{2}$ tests, with $95 \%$ CIs. To evaluate the independent association of different variables on ICH (five to seven ideal metrics), we used univariate and multivariable Poisson regression models adjusting for sex, age groups, site, education level and socioeconomic status and calculated prevalence ratios with 95\% CIs. All $\mathrm{P}$ values were two-sided and a $\mathrm{P}<0.05$ was considered to be statistically significant. STATA V.10 (StataCorp, College Station, Texas, USA) was used for all analyses.

\section{RESULTS}

A total of 3058 of $3618(84.5 \%)$ of the CRONICAS cohort participants had complete information for analysis. Table 1 presents the baseline sociodemographic characteristics by sex. Mean age of the study population was 55.6 years ( $\mathrm{SD} \pm 12.7$ years) and $51.3 \%$ female. Baseline education level and socioeconomic status differed by sex with more females $(55.6 \%)$ than males $(35.6 \%)$ having completed only primary school or less $(\mathrm{P}<0.001)$. More females $(36.1 \%)$ were in the poorest tertile of socioeconomic status compared with males $(25.8 \%)(\mathrm{P}<0.001)$.

\section{Prevalence of ICH factors}

Figure 1 shows the prevalence of poor, intermediate and ideal for each cardiovascular health metric in the total population, weighted for the population size of each study site (Lima, Tumbes, rural and urban Puno). The distribution of number of ICH factors overall and by sex is shown in online supplementary figure $1 \mathrm{a}$.

For ICH factors, ideal fasting plasma glucose was the most prevalent while ideal total cholesterol was the least prevalent. Ideal blood pressure was higher in females than males $(63.4 \%$ vs $46.5 \%$, respectively) but ideal total cholesterol was lower in females compared with males $(48.9 \%$ vs $55.1 \%$, respectively). Nearly three-quarters of both females and males had ideal fasting plasma glucose $(73.4 \%$ vs $74.8 \%$, respectively) (see online supplementary table 2 ).

\section{Prevalence of ICH behaviours}

The distribution of number of ICH behaviours overall and by sex is shown in online supplementary figure $1 \mathrm{~b}$ For $\mathrm{ICH}$ behaviours, non-smoking was the most prevalent while ideal diet and high physical activity were the least prevalent. Females had higher prevalence of non-smoking than males $(95.3 \%$ vs $77.1 \%$, respectively). Only one in four females and one in three males had normal BMI. Ideal physical activity levels were low: females $4.0 \%$ and males $9.3 \%$. Fruit and vegetable consumption was similar between females and males $(7.1 \%$ vs $4.9 \%$, respectively) (online supplementary table 2).

\section{Number of ICH factors and behaviours}

Table 2 shows the results for the cardiovascular health metrics by sociodemographic characteristics. No one had all 7 ideal metrics; only $41(1.3 \%)$ had 6 ideal health metrics and 322 $(10.5 \%)$ had $\leq 1$ ideal health metric. Fewer participants had ICH (5-7 ideal metrics) (12.7\%) than had poor cardiovascular health 
Table 1 Characteristics of the study population overall and by sex $(n=3058)$

\begin{tabular}{|c|c|c|c|c|c|c|c|c|}
\hline & \multirow[b]{3}{*}{$\mathrm{N}$} & \multicolumn{2}{|c|}{ Total population } & \multicolumn{2}{|l|}{ Female } & \multicolumn{2}{|l|}{ Male } & \multirow[b]{3}{*}{$P$ value } \\
\hline & & $\mathrm{N}$ & $(\%)$ & $\mathrm{N}$ & $(\%)$ & $\mathrm{N}$ & $(\%)$ & \\
\hline & & 3058 & 100 & 1569 & 51.30 & 1488 & 48.70 & \\
\hline Age group (years) & 3057 & & & & & & & 0.650 \\
\hline $35-44$ & & 739 & 24.20 & 372 & 23.70 & 367 & 24.70 & \\
\hline $45-54$ & & 786 & 25.70 & 417 & 26.60 & 369 & 24.80 & \\
\hline $55-64$ & & 773 & 25.30 & 399 & 25.40 & 374 & 25.10 & \\
\hline$\geq 65$ & & 759 & 24.80 & 381 & 24.30 & 378 & 24.80 & \\
\hline Site & 3058 & & & & & & & 0.861 \\
\hline Lima & & 1018 & 33.30 & 526 & 33.50 & 492 & 33.00 & \\
\hline Puno urban & & 503 & 16.50 & 257 & 16.40 & 246 & 16.50 & \\
\hline Puno rural & & 519 & 17.00 & 273 & 17.40 & 246 & 16.50 & \\
\hline Tumbes & & 1018 & 33.30 & 513 & 32.70 & 505 & 33.90 & \\
\hline Education & 3056 & & & & & & & $<0.001$ \\
\hline Primary or less & & 1401 & 45.80 & 872 & 55.60 & 529 & 35.60 & \\
\hline Secondary & & 1009 & 33.00 & 435 & 27.70 & 574 & 38.60 & \\
\hline Superior & & 646 & 21.10 & 262 & 16.70 & 384 & 25.80 & \\
\hline Wealth index & 3058 & & & & & & & $<0.001$ \\
\hline Lowest & & 950 & 31.00 & 566 & 36.10 & 384 & 25.80 & \\
\hline Middle & & 1052 & 34.40 & 527 & 33.60 & 525 & 35.30 & \\
\hline Highest & & 1056 & 34.50 & 476 & 30.30 & 580 & 39.00 & \\
\hline
\end{tabular}

(0-2 ideal metrics) (31.8\%). Females, aged 35-44 years, those living in rural Puno and those in the lowest socioeconomic tertile had the highest percentage of ICH (table 2).

The mean ICH score was 3.09 overall, with females, age group 35-44 years, rural Puno, superior education and lowest socioeconomic tertile had the highest mean lifestyle scores (table 2). Males, age groups 55-64 and $\geq 65$ years, semiurban Tumbes, primary education or less and highest socioeconomic status had the highest percentage of poor cardiovascular health (table 2).

Table 3 shows the association between the sociodemographic variables and $\mathrm{ICH}$ using univariate and multivariate analyses. Compared with age 35-44 years, the age groups 55-64 years and $\geq 65$ years were less likely to have less ICH after adjusting for sex, site, education and socioeconomic status $(\mathrm{P}<0.001)$. Compared with urban Lima, and after adjustment for sex, age, education and socioeconomic status, individuals living in rural Puno were more likely to have $\mathrm{ICH}$, and those living in rural Tumbes less ICH $(\mathrm{P}<0.001)$. Compared with those in the lowest tertile of socioeconomic status, those in the middle and highest tertiles were less likely to have ICH $(\mathrm{P}<0.001)$ (table 3).

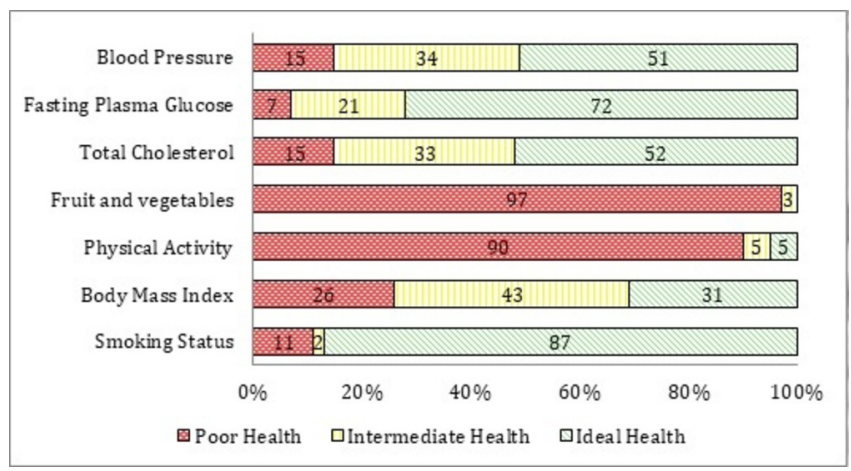

Figure 1 Prevalence estimates for poor, intermediate and ideal cardiovascular health for each of the seven American Heart Association Cardiovascular Health metrics in adults aged $\geq 35$ years $(n=3058)$.
Of 133 participants with a self-reported history of CVD, fewer with CVD history had ICH $(8.2 \%$; 95\% CI 3.6\% to $13.0 \%)$ compared without prior history of CVD (18.4\%; 95\% CI 17.0\% to $19.7 \%)(\mathrm{P}=0.003)$.

Self-report of 'very good' health was low $(n=54,1.8 \%)$ in this population; whereas 'bad' or 'very bad' health was more frequently reported $(n=251,8.2 \%)$. Most individuals reported 'regular' or 'good' health $(58.0 \%$ and $32.0 \%$, respectively). There were more individuals who reported 'very good' or 'good' health who had ICH compared with those who did not report 'very good' or 'good' health $(39.2 \%$; 95\% CI 35.1\% to $43.3 \%$ vs $32.6 \%$; $95 \% \mathrm{CI} 30.8 \%$ to $34.5 \%, \mathrm{P}=0.003$, respectively). Eleven per cent of individuals who reported 'bad' or 'very bad' health met the ICH metrics (95\% CI 8.4\% to $13.6 \%$ ).

\section{Treatment and control of health factors}

Online supplementary table 1 shows medication use and control of blood pressure, TC and fasting plasma glucose. There were $321(10.5 \%)$ participants taking antihypertensive medications, $58(1.9 \%)$ participants taking cholesterol-lowering medications and $94(3.1 \%)$ participants taking glucose-lowering medications in the study population. Of those taking antihypertensive medications, only $77(24.0 \%)$ had their blood pressure controlled. Of those taking cholesterol-lowering medications, 26 (44.8\%) had their cholesterol at goal, and $32(55.2 \%)$ had their LDL controlled. Of those taking glucose-lowering medication, 17 (18.1\%) had their glucose controlled.

\section{DISCUSSION}

The prevalence of ICH is very low in Peru. Achieving such ideal health status is important as this positive health metric includes factors and behaviours that protect and prevent individuals from developing CVD. In our study, none of the 3058 participants from 4 different geographical regions were found to have all 7 of the ideal health metrics. This is the first study to find substantial differences in $\mathrm{ICH}$ metrics among the Peruvian population by sex, age group, site, education level and socioeconomic status. 
Table 2 Cardiovascular health metrics by sociodemographic variables

\begin{tabular}{|c|c|c|c|c|c|}
\hline & & $\begin{array}{l}\text { Ideal cardiovascular health } \\
\text { (5-7 ideal metrics) }\end{array}$ & $\begin{array}{l}\text { Intermediate cardiovascular } \\
\text { health (3-4 ideal metrics) }\end{array}$ & $\begin{array}{l}\text { Poor cardiovascular health } \\
\text { (0-2 ideal metrics) }\end{array}$ & $\begin{array}{l}\text { Mean cardiovascular health } \\
\text { score (out of } 7 \text { ) }\end{array}$ \\
\hline & $\mathrm{N}$ & $\%(95 \% \mathrm{Cl})$ & $\%(95 \% \mathrm{Cl})$ & $\%(95 \% \mathrm{Cl})$ & Mean $(95 \% \mathrm{Cl})$ \\
\hline Total & 3058 & $12.7(11.5$ to 13.9$)$ & 55.6 (53.8 to 57.4$)$ & 31.8 (30.1 to 33.4 ) & 3.09 (3.05 to 3.13 ) \\
\hline \multicolumn{6}{|l|}{ Sex } \\
\hline Female & 1569 & 13.2 (11.6 to 15.0$)$ & 57.7 (55.3 to 60.2$)$ & 29.1 (26.9 to 31.4) & 3.17 (3.11 to 3.23 ) \\
\hline Male & 1489 & 12.1 (10.5 to 13.8$)$ & $53.3(50.8$ to 55.9$)$ & 34.6 (32.2 to 37$)$ & 3.01 (2.94 to 3.07 ) \\
\hline \multicolumn{6}{|l|}{ Age group (years) } \\
\hline $35-44$ & 739 & 16.0 (13.5 to 18.8$)$ & 60.2 (56.6 to 63.7 ) & 23.8 (20.9 to 27 ) & 3.33 (3.25 to 3.42 ) \\
\hline $45-54$ & 786 & 13.7 (11.5 to 16.3$)$ & 56.2 (52.7 to 59.7 ) & 30 (26.9 to 33.3 ) & 3.13 (3.04 to 3.22 ) \\
\hline $55-64$ & 773 & 8.9 (7.1 to 11.2 ) & 52.9 (49.4 to 56.4$)$ & 38.2 (34.8 to 41.6 ) & 2.88 (2.8 to 2.97 ) \\
\hline$\geq 65$ & 759 & 12.1 (10 to 14.6$)$ & 53.1 (49.5 to 56.6 ) & 34.8 (31.5 to 38.3 ) & 3.03 (2.94 to 3.11 ) \\
\hline \multicolumn{6}{|l|}{ Site } \\
\hline Lima & 1018 & 12.4 (10.5 to 14.6$)$ & 55.1 (52.0 to 58.2 ) & 32.5 (29.7 to 35.5 ) & 3.06 (2.98 to 3.13 ) \\
\hline Puno-urban & 503 & 13.7 (11 to 17$)$ & 63.0 (58.7 to 67.2 ) & 23.3 (19.8 to 27.2 ) & 3.26 (3.16 to 3.37 ) \\
\hline Puno-rural & 519 & 23.5 (20 to 27.4$)$ & 60.7 (56.4 to 64.8$)$ & 15.8 (12.9 to 19.2$)$ & 3.64 (3.54 to 3.74 ) \\
\hline Tumbes & 1018 & 6.9 (5.5 to 8.6$)$ & 49.8 (46.7 to 52.9 ) & 43.3 (40.3 to 46.4 ) & 2.76 (2.69 to 2.83 ) \\
\hline \multicolumn{6}{|l|}{ Education } \\
\hline Primary or less & 1401 & 12.3 (10.7 to 14.2$)$ & 55.5 (52.8 to 58.1$)$ & 32.2 (29.8 to 34.7 ) & 3.10 (3.03 to 3.16 ) \\
\hline Secondary & 1009 & 13.6 (11.6 to 15.8$)$ & 54.6 (51.5 to 57.7$)$ & 31.8 (29 to 34.8 ) & 3.08 (3 to 3.16 ) \\
\hline Superior & 646 & 11.9 (9.6 to 14.7$)$ & 57.4 (53.6 to 61.2$)$ & 30.7 (27.2 to 34.3$)$ & 3.10 (3 to 3.19 ) \\
\hline \multicolumn{6}{|l|}{ Socioeconomic status } \\
\hline Lowest (poorest) & 950 & 16.8 (14.6 to 19.4 ) & 59.0 (55.8 to 62.0$)$ & 24.2 (21.6 to 27$)$ & 3.31 (3.23 to 3.39 ) \\
\hline Middle & 1052 & $10.8(9.1$ to 12.9$)$ & 56.0 (53.0 to 59.0$)$ & 33.2 (30.4 to 36.1 ) & 3.05 (2.98 to 3.12 ) \\
\hline Highest (richest) & 1056 & 10.7 (9 to 12.7$)$ & $52.2(49.2$ to 55.2$)$ & 37.1 (34.3 to 40.1$)$ & 2.94 (2.86 to 3.01$)$ \\
\hline
\end{tabular}

Rural communities, and rural women in particular, are considered to have health inequalities, such as inadequate access to information and limited public investment in health services, housing and education. Poverty affects those in urban and rural areas and around $30 \%$ of the population resides at the poverty line, or approximately 9 million people, so this study provides insight into the cardiovascular health of a substantial portion of this population.

The prevalence of having seven ICH metrics is very low globally, ranging from $0.3 \%$ to $15 \%$ and varies by geographical location, age, sex, ethnicity and education level. ${ }^{5-102122}$ Overall, the mean ICH score in Peru was low at 3.29 (out of 7) and was lower

Table 3 Association between sociodemographic characteristics and ideal cardiovascular health (5-7 ideal metrics) ( $\mathrm{n}=3058)$

\begin{tabular}{|c|c|c|c|c|c|c|}
\hline & \multicolumn{3}{|l|}{ Univariate } & \multicolumn{3}{|c|}{ Multivariate, adjusted for all other variables } \\
\hline & PR & $95 \% \mathrm{Cl}$ & $P$ value & PR & $95 \% \mathrm{Cl}$ & $P$ value \\
\hline \multicolumn{7}{|l|}{ Sex } \\
\hline Female & Reference & & & Reference & & \\
\hline Male & 0.92 & 0.75 to 1.12 & 0.391 & 0.97 & 0.79 to 1.19 & 0.760 \\
\hline \multicolumn{7}{|l|}{ Age group (years) } \\
\hline $35-44$ & Reference & & & Reference & & \\
\hline $45-54$ & 0.86 & 0.66 to 1.12 & 0.259 & 0.85 & 0.65 to 1.10 & 0.219 \\
\hline $55-64$ & 0.56 & 0.42 to 0.75 & $<0.001$ & 0.54 & 0.40 to 0.74 & $<0.001$ \\
\hline$\geq 65$ & 0.76 & 0.58 to 1.00 & 0.048 & 0.71 & 0.53 to 0.96 & 0.028 \\
\hline \multicolumn{7}{|l|}{ Site } \\
\hline Lima & Reference & & & Reference & & \\
\hline Puno-urban & 1.11 & 0.83 to 1.49 & 0.492 & 1.09 & 0.79 to 1.50 & 0.594 \\
\hline Puno-rural & 1.90 & 1.48 to 2.44 & $<0.001$ & 1.61 & 1.20 to 2.16 & 0.001 \\
\hline Tumbes & 0.56 & 0.41 to 0.74 & $<0.001$ & 0.52 & 0.39 to 0.71 & $<0.001$ \\
\hline \multicolumn{7}{|l|}{ Education } \\
\hline Primary or less & Reference & & & Reference & & \\
\hline Secondary & 1.10 & 0.88 to 1.38 & 0.407 & 1.05 & 0.81 to 1.35 & 0.730 \\
\hline Superior & 0.97 & 0.74 to 1.26 & 0.796 & 0.96 & 0.68 to 1.35 & 0.813 \\
\hline \multicolumn{7}{|c|}{ Socioeconomic status } \\
\hline Lowest (poorest) & Reference & & & Reference & & \\
\hline Middle & 0.64 & 0.51 to 0.82 & $<0.001$ & 0.73 & 0.56 to 0.95 & 0.02 \\
\hline Highest (richest) & 0.64 & 0.5 to 0.81 & $<0.001$ & 0.75 & 0.55 to 1.01 & 0.06 \\
\hline
\end{tabular}


than studies of the US adults aged $20-60$ years (3.4-4.7). ${ }^{923}$ Rural Tumbes had a mean ICH score of 2.82, which is the lowest score in North and South America (compared with those reported in the literature)- worse than the most unhealthy states in the USA. ${ }^{9}$ Rural Puno and the younger age group (35-44 years) had a higher prevalence than the other sites and age groups of ICH. Prior studies have noted that younger ages are healthier. While only one study looked at a rural population and found $1.0 \%$ had all seven ICH metrics and only $7 \%$ had $\leq 1$ metric. $^{24}$

In general, ICH factors were more frequent than health behaviours, for example, nearly $75 \%$ of participants had normal fasting glucose and over half had normal blood pressure and normal cholesterol. Of those reporting medication use for blood pressure, diabetes or cholesterol, less than half were controlled to goal. This trend has been described previously, ${ }^{24}$ with much lower awareness and control of chronic conditions in low-income and middle-income countries than in high-income countries.

The prevalence of smoking is lower in our study $(4.1 \%$ in females and $19.9 \%$ in males) compared with prior studies in urban areas from Peru, which found age-standardised smoking prevalence of $12.6 \%$ for females and $31.1 \%$ for males using a similar definition. ${ }^{12}$ Other Latin American populations have even higher prevalence of risk factors, including smoking prevalence of up to $45 \%,{ }^{25}{ }^{26}$ which would further decrease the mean ICH score and result in an even lower prevalence of $\mathrm{ICH}$. The low prevalence of high physical activity and healthy diet were major contributors to the low prevalence of ICH.

The rural communities had the largest difference in percentage of poor cardiovascular health $(11.8 \%$ in rural Puno vs $41.5 \%$ in rural Tumbes) and was the highest socioeconomic tertile (30.8\%). The rural sites have different cardiovascular health profiles than those residing in Peru's capital. In the USA, different prevalence of poor cardiovascular health is seen (6.7\% in Colorado to $16.2 \%$ in West Virginia), but the variation is lower than this study. ${ }^{5-9}$ Rural Puno is healthier than rural Tumbes even though both populations experience poverty. Rural Puno is located high in the Andean mountains and subsistence farming is common with more traditional diets, consisting mainly of starches (potatoes) and with limited meat; whereas, those living in rural Tumbes have a poor diet with fried meat and fish. Potential factors in Tumbes to account for this difference include hotter climate in Tumbes, different degree of genetic predisposition to developing metabolic derangements and different metabolism due to potential undernourishment during childhood.

Improving the population mean ICH score, by moving from poor to intermediate or intermediate to ideal in any metric, would improve the cardiovascular health to a level similar to that in the worst states in America; however, which specific metric will have the most impact in this population remains unknown. Prior studies suggest that population-based strategies to improve diet and exercise are effective. ${ }^{27}$ The high prevalence of overweight and obesity in this population appears to be associated with these metrics and interventions may decease CVD risk factors. ${ }^{5}{ }^{13}$ Possible interventions are needed to improve access to and consumption of fruits and vegetables, decreasing obesity, improving the built environment to facilitate exercise, enforcing smoking bans in workplaces and public spaces as well as improving primary healthcare access to deliver preventative health behaviour counselling and perform a health risk assessment. ${ }^{28}$

As with any cross-sectional, population-based study, there may have been selection bias due to the 'healthy worker effect' and an

\section{Key messages}

What is already known about this subject? Ideal cardiovascular health is an important predictor of health outcomes and varies by geography and other sociodemographic characteristics.

\section{What might this study add?}

This study describes the prevalence of seven ideal cardiovascular health factors and behaviours in a resource-constrained setting. No one had all seven ideal metrics; only $41(1.3 \%)$ had 6 ideal health metrics and $322(10.5 \%)$ had $\leq 1$ ideal health metric. Females, aged 35-44 years, those living in rural Puno, and those in the lowest socioeconomic tertile had the highest percentage of ideal cardiovascular health.

\section{How might this impact on clinical practice?}

The low prevalence of ideal cardiovascular health in this setting is important for clinicians and policy makers to recognise and can serve as a benchmark and aid in the development of cardiovascular disease prevention programmes in a resourcelimited country with a substantial population living in poverty in rural and urban communities.

overestimation of ICH. The low prevalence of physical activity (which includes both leisure-time and transportation-related) is likely an underestimation of actual physical activity. Future studies could include daily step tracking. Fruit and vegetable intake as a surrogate for diet, which has a protective effect on CVD at high intake ${ }^{29}$ but may overestimate true prevalence of ICH since only $3 \%$ met at least 4 of the 5 components of the DASH diet and $25 \%$ met this criteria. Medications were self-reported and compliance was not confirmed.

\section{CONCLUSIONS}

We report low prevalence rates of healthy lifestyle. The metrics with the lowest prevalence and therefore highest potential room for improvement are health behaviours, including diet quality, physical activity and body weight. This study can serve as a benchmark if ICH and aid in the development of CVD prevention programmes in a resource-limited country with a substantial population living in poverty in rural and urban communities.

Correction notice Since this paper was first published online the funding statement has been updated. Reference citations in the text have also been updated

Contributors CPB and JJM conceived the idea of the manuscript. CPB drafted the first version of the manuscript and led the statistical analysis with support of JZL and AB-O. JJM, RHG, WC and LS conceived, designed and supervised the overall study. JJM, AB-O and WC coordinated and supervised fieldwork activities in Lima, Tumbes and Puno. All authors participated in writing of manuscript, provided important intellectual content and gave their final approval of the version submitted for publication.

Funding This CRONICAS Cohort Study was established with federal funds from the US National Heart, Lung, and Blood Institute, National Institutes of Health, Department of Health and Human Services, under contract no HHSN268200900033C. AB-O is a Research Training Fellow in Public Health and Tropical Medicine (103994/Z/14/Z) and LS is a Senior Clinical Fellow (098504/Z/12/Z), both funded by Wellcome Trust. WC was further supported by a Pathway to Independence Award (ROOHL096955) from the National Heart, Lung and Blood Institute. JJM acknowledges receiving additional support from the Alliance for Health Policy and Systems Research (HQHSR1206660), DFID/MRC/Wellcome Global Health Trials (MR/M007405/1), Fogarty International Center (R21TW009982, D71TW010877), Grand Challenges Canada (0335-04), International Development Research Center Canada (106887, 108167), Inter-American Institute for Global Change Research (IAI CRN3036), Medical Research Council (MR/P008984/1 
MR/P024408/1, MR/P02386X/1), National Cancer Institute (1P20CA217231), National Heart, Lung and Blood Institute (HHSN268200900033C, 5U01HL114180, 1UM1HL134590), National Institute of Mental Health (1U19MH098780), Swiss National Science Foundation (40P740-160366), Wellcome Trust (074833/Z/04/Z, 093541/Z/10/Z, 107435/Z/15/Z, 103994/Z/14/Z, 205177/Z/16/Z) and the World Diabetes Foundation (WDF15-1224).

Competing interests None declared.

Patient consent Obtained.

Ethics approval Ethics approval for this study protocol was obtained from the Institutional Review Boards at Universidad Peruana Cayetano Heredia and A.B. PRISMA in Lima, Peru, and at the Johns Hopkins Bloomberg School of Public Health in Baltimore, MD, USA.

Provenance and peer review Not commissioned; externally peer reviewed.

Data sharing statement Technical appendix, statistical code and dataset available on request from the corresponding author at jaime.miranda@upch.pe. Applications will only be granted and data provided after agreement from our contributing providers.

Open access This is an open access article distributed in accordance with the terms of the Creative Commons Attribution (CC BY 4.0) license, which permits others to distribute, remix, adapt and build upon this work, for commercial use, provided the original work is properly cited. See: http://creativecommons.org/licenses/by/4.0/

(c) Article author(s) (or their employer(s) unless otherwise stated in the text of the article) 2018. All rights reserved. No commercial use is permitted unless otherwise expressly granted.

\section{REFERENCES}

1 Go AS, Mozaffarian D, Roger VL, et al. Heart disease and stroke statistics--2013 update: a report from the American Heart Association. Circulation 2013;127:e6-e245.

2 Lloyd-Jones DM, Hong Y, Labarthe D, et al. Defining and setting national goals for cardiovascular health promotion and disease reduction: the American Heart Association's strategic Impact Goal through 2020 and beyond. Circulation 2010;121:586-613.

3 Kulshreshtha A, Vaccarino V, Judd SE, et al. Life's Simple 7 and risk of incident stroke: the reasons for geographic and racial differences in stroke study. Stroke 2013:44:1909-14.

4 Herdy AH, López-Jiménez F, Terzic CP, et al. South American guidelines for cardiovascular disease prevention and rehabilitation. Arq Bras Cardiol 2014;103:1-31.

5 Ford ES, Li C, Zhao G, et al. Trends in the prevalence of low risk factor burden for cardiovascular disease among United States adults. Circulation 2009;120:1181-8.

6 Yang Q, Cogswell ME, Flanders WD, et al. Trends in cardiovascular health metrics and associations with all-cause and CVD mortality among US adults. JAMA 2012;307:1273-83.

7 Dong C, Rundek T, Wright CB, et al. Ideal cardiovascular health predicts lower risks of myocardial infarction, stroke, and vascular death across whites, blacks, and hispanics: the northern Manhattan study. Circulation 2012;125:2975-84.

8 Folsom AR, Yatsuya $H$, Nettleton JA, et al. Community prevalence of ideal cardiovascular health, by the American Heart Association definition, and relationship with cardiovascular disease incidence. J Am Coll Cardiol 2011:57:1690-6.

9 Fang J, Yang Q, Hong Y, et al. Status of cardiovascular health among adult Americans in the 50 States and the District of Columbia, 2009. J Am Heart AssoC 2012;1:e005371.
10 Bambs C, Kip KE, Dinga A, et al. Low prevalence of "ideal cardiovascular health" in a community-based population: the heart strategies concentrating on risk evaluation (Heart SCORE) study. Circulation 2011;123:850-7.

11 Medina-Lezama J, Morey-Vargas OL, Zea-Díaz H, et al. Prevalence of lifestyle-related cardiovascular risk factors in Peru: the PREVENCION study. Rev Panam Salud Publica 2008:24:169-79.

12 Shay CM, Ning H, Allen NB, et al. Status of cardiovascular health in US adults: prevalence estimates from the National Health and Nutrition Examination Surveys (NHANES) 2003-2008. Circulation 2012;125:45-56.

13 Bernabe-Ortiz A, Benziger CP, Gilman RH, et al. Sex differences in risk factors for cardiovascular disease: the Peru Migrant Study. PLoS One 2012;7:e35127.

14 Velasquez-Melendez G, Felisbino-Mendes MS, Matozinhos FP, et al. Ideal cardiovascular health prevalence in the Brazilian population - National Health Survey (2013). Rev Bras Epidemiol 2015;18 Suppl 2:97-108.

15 Miranda JJ, Bernabe-Ortiz A, Smeeth L, et al. Addressing geographical variation in the progression of non-communicable diseases in Peru: the CRONICAS cohort study protocol. BMJ Open 2012;2:e000610.

16 Howe LD, Galobardes B, Matijasevich A, et al. Measuring socio-economic position for epidemiological studies in low- and middle-income countries: a methods of measurement in epidemiology paper. Int J Epidemiol 2012;41:871-86.

17 Sacks FM, Svetkey LP, Vollmer WM, et al. Effects on blood pressure of reduced dietary sodium and the Dietary Approaches to Stop Hypertension (DASH) diet. DASH-Sodium Collaborative Research Group. N Engl J Med 2001;344:3-10.

18 Dauchet $L$, Amouyel P, Hercberg S, et al. Fruit and vegetable consumption and risk of coronary heart disease: a meta-analysis of cohort studies. J Nutr 2006;136:2588-93.

19 Hallal PC, Gomez LF, Parra DC, et al. Lessons learned after 10 years of IPAQ use in Brazil and Colombia. J Phys Act Health 2010;7(Suppl 2):S259-64.

20 Chobanian AV, Bakris GL, Black HR, et al. The seventh report of the joint national committee on prevention, detection, evaluation, and treatment of high blood pressure: the JNC 7 report. JAMA 2003;289:2560-72.

21 Expert panel on detection, evaluation, and treatment of high blood cholesterol in adults. Executive summary of the third report of the National Cholesterol Education Program (NCEP) expert panel on detection, evaluation, and treatment of high blood cholesterol In adults (Adult Treatment Panel III). JAMA 2001;285:2486-97.

22 Younus A, Aneni EC, Spatz ES, et al. A systematic review of the prevalence and outcomes of ideal cardiovascular health in US and non-US populations. Mayo Clin Proc 2016:91:649-70.

23 Huffman MD. Cardiovascular health in low- and middle-income countries. Curr Prob/ Cardiol 2014;39:399-419.

24 Chow CK, Teo KK, Rangarajan S, et al. Prevalence, awareness, treatment, and control of hypertension in rural and urban communities in high-, middle-, and low-income countries. JAMA 2013;310:959-68.

25 Lloyd-Sherlock P, Beard J, Minicuci N, et al. Hypertension among older adults in low- and middle-income countries: prevalence, awareness and control. Int J Epidemiol 2014;43:116-28.

26 Miranda JJ, Herrera VM, Chirinos JA, et al. Major cardiovascular risk factors in Latin America: a comparison with the United States. The Latin American Consortium of Studies in Obesity (LASO). PLoS One 2013;8:e54056.

27 Giovino GA, Mirza SA, Samet JM, et al. Tobacco use in 3 billion individuals from 16 countries: an analysis of nationally representative cross-sectional household surveys. Lancet 2012;380:668-79.

28 Artinian NT, Fletcher GF, Mozaffarian D, et al. Interventions to promote physical activity and dietary lifestyle changes for cardiovascular risk factor reduction in adults: a scientific statement from the American Heart Association. Circulation 2010;122:406-41.

29 Uthman OA, Hartley L, Rees K, et al. Multiple risk factor interventions for primary prevention of cardiovascular disease in low- and middle-income countries. Cochrane Database Syst Rev 2015:CD011163. 